\title{
EXPLORATORY RESEARCH TO BETTER UNDERSTAND THE DIFFICULTIES OF TAKING SUSTAINABILITY INTO ACCOUNT IN THE EVOLUTION OF ENGINEERING EDUCATION AND TRAINING
}

\author{
Lou GRIMAL ${ }^{1}$, Jules BAUDRY ${ }^{2}$, Pelgrim CHARRAUD², Rémi CÉRET ${ }^{2}$ and Nadège \\ TROUSSIER ${ }^{1}$ \\ ${ }^{1}$ ICD, CREIDD, Université de Technologie de Troyes, Troyes, France \\ ${ }^{2}$ Université de Technologie de Troyes, Troyes, France
}

\begin{abstract}
Humanity's entrance into the Anthropocene forces us to question the role of technology because of its impacts on the environment. The stake is the viability of the Earth system for humans. Engineers producing a large part of these impacting techniques are not trained in sustainable issues (environmental, social and economic ones - in a systemic way). An exploratory workshop was held at a French University of Technology to study the development of new engineering training courses on issues of strong sustainability. During this workshop, the participants were placed into the current French institutional framework and were asked to develop a new training within this specific framework. The hypothesis formulated at the end of this experiment is that institutional frameworks can be an obstacle to the production of new training adapted to the transition phenomenon to respond to the increasing risk of socio-ecological catastrophes. This experiment was conducted as part of a heuristic approach and opens new perspectives for the evolution of training as well as institutional frameworks in higher education and research.
\end{abstract}

\section{Keywords: Ecological catastrophes, engineering studies, education, institutional framework}

\section{INTRODUCTION}

The entrance of humanity into the Anthropocene [1] requires us to rethink technology by considering the impacts technical tools have on the ecosystems. All these techniques used by man (our activities in a broad sense) and their impacts can be understood called "anthroposphere". This anthroposphere is in constant exchange with the biosphere, which is defined by all ecosystems, living organisms evolving in their living environments. These two spheres interact: people draw their raw materials from the biosphere to meet their needs. This interaction seems one-sided. Indeed, the impact of the anthroposphere on the biosphere is such that the latter is struggling to recover. Indeed, each year, the rate of resource extraction exceeds that of resource regeneration, while the quantity of emissions exceeds that which the biosphere is capable of absorbing to sustainably ensure our living conditions. In other words, the current metabolism of the anthroposphere in the biosphere is unsustainable and compromises the viability of the earth system [5]. As a result, the methods used to design techniques take little account of the biosphere's carrying capacity. In contemporary societies, engineers are poorly trained in the impacts of their work on ecosystems. Engineers apply "scientific principles to solve problems to improve society. Engineering is a service profession. However, day-to-day engineering is more often focused on technological rather than human concerns" [6]. The training of engineers in environmental issues is therefore essential to develop technologies that respond to societal challenges [6] and to make the links between anthroposphere and biosphere sustainable. Our society seems to develop technologies for only certain categories of the population. Indeed, $90 \%$ of engineers design for $10 \%$ of the world's population (the richest people) [7]. There is therefore a real challenge in training engineers in environmental and societal issues to prepare them for future socio-ecological disasters. 
The objective of this document is to question the limits of the evolution of engineering education in the face of ecological challenges. It reports the results of a workshop undertaken to test whether current institutional frameworks are relevant for integrating sustainability issues into engineering education. The article presents and analyses the results of this workshop and identifies the difficulties posed by institutional frameworks for the evolution of these trainings.

The whole experience takes place in a French context. Indeed, this workshop is based on the functioning of the French institution that authorizes engineering schools to deliver state diplomas: The Commission des Titres d'ingénieurs (CTI). It seems interesting to make a quick review of the history of engineering in France. At the end of the $18^{\text {th }}$ Century, the first French engineers were destined to serve the State, by planning the territory and the military force [9]. In the light of the first industrial revolution, engineers were assigned to the management of the booming industry. The CTI institution was created in 1934. Its objective is to regulate training in engineering schools and to supervise private initiative.

\section{RESEARCH METHODOLOGY}

\subsection{Descriptive study}

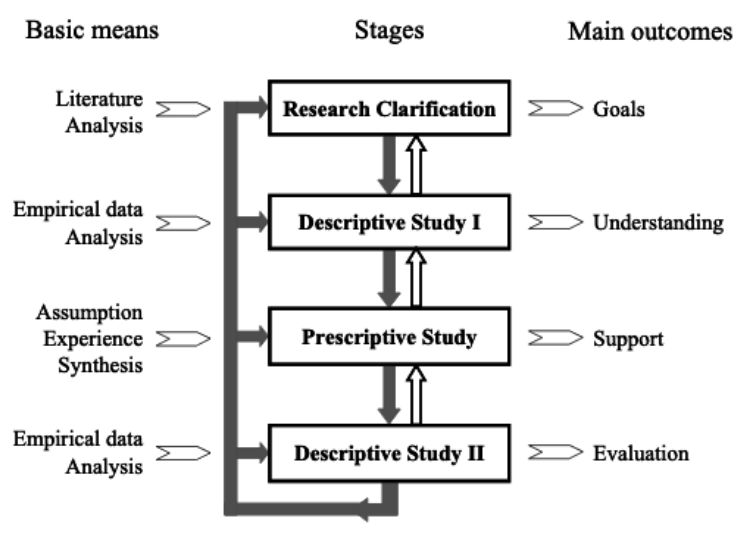

Figure 1. Design Research Methodology

Our methodology can be positioned in the Design Research Methodology [8] which is represented in Figure 1. This paper can be positioned at the "Descriptive Study I" stage. Indeed, the main goal of the researchers being the integration of sustainable stakes in engineering education, the main goal was to collect data to "elaborate the initial description of the existing situation". This paper describes a workshop that tests the capacity of an institutional training framework to integrate societal and environmental issues. Thus, the goal of this experiment is to understand the difficulties of integration of sustainability in the evolution of current engineering programmes.

\subsection{Details of the study}

The exploration work had been done based on a one-day workshop at the University of Technology of Troyes during its 25-year anniversary. The workshop was open to all students and employees of the university and it was announced as "workshop organized by students on sustainability: permaengineering and sustainability", among 7 other workshops.

It was the most successful workshop with $33 \%$ of the participants within the 7 workshops. Four students from master's and engineering curricula were leading the workshop. 15 participants came to the workshop, not all at the same time, and participated in two groups of 6 persons each. During the workshop the number of participants present did not fall below 11. This group of participants was composed of students (one of them coming from another European university), employees (administrative and teachers) and direction staff representatives.

The workshop has been led in 4 steps:

- Step 1: Introduction of the challenges to meet before the end of the century and presentation of the objectives of the workshop (scientific content)

- $\quad$ Step 2: Choice of a domain from the CTI framework (domain of expertise)

- Step 3: Mind map of the constraints for the new curricula they want to create

- Steep 4: Proposal of topics for contents and modality for new competencies on a "sustainability 
wheel"

The two groups went to the four steps. People from undergraduate, research, teaching and direction staff constituted each group. The productions of the groups were kept and analysed after the workshop.

\section{RESULTS}

Below are the results the participants got following the four steps of the workshop.

\subsection{Step 1: Literature review presentation}

A slide show of about 30 slides has been presented to explain the current environmental challenges. The presentation was made around pictures from an academic literature review and a synthesis of the global stakes.

\subsection{Step 2: Domain of expertise}

The CTI framework is composed of the following dimensions: agriculture, agronomy, agri-food, chemistry, proceeds engineering, medical engineering, earth sciences, materials, civil engineering, building, development, environment, mechanics, energy, electricity, electrical engineering, automation, electronics, telecoms and network, computer science, information systems, mathematics, modelling, industrial engineering, production, logistics. The combination of two dimensions (not more) is possible with defined words "and", "or", for".

Both groups faced difficulties to choose a domain from this framework and had the willingness to build a pedagogical curriculum out of the framework. One group did so while the second one finally decided to choose to combine three domains of the framework to address a wider scope. The first group chooses to start on a common base of skills: "common foundation of perma-engineering ". They decided not to respect the CTI framework because the competences had to be transversal and not be restricted to one engineering domain. The second group chooses the formation agriculture, mechanics and energy: training the engineer in sustainable agriculture that considers today's mechanical and energy constraints. Both groups took 15 minutes to choose and did not respect CTI framework from the start while it was the only rule the organisers gave them.

\subsection{Step 3: Mind map of constraints}

Each group has elaborated a mind map of the constraints. Both groups took 45 minutes to build the mind map.

Group 1 identified thirteen constraints that we can group into three sections:

- Personal commitment of people: personal values, creativity, open-mindedness (addressing everyone, including those with opposing values).

- The complexity of the knowledge to be acquired on sustainability: knowledge of the issues (social, biodiversity, climate and resources), problematized knowledge (intelligibility of knowledge, reticence), global transversally and complexity of the issues.

- The institutional framework: training time ( 2 or 3 years), training of people, dissemination of the approach, policy, the weight of industrialists, institutional organizations, CTI.

Group 2 identified sixteen constraints that we can also group into three sections:

- Personal commitment of people: competence and convictions of teachers/researchers, ethics, consumption.

- Specific knowledge: design (recycling, reuse), technology, land use (deforestation, food waste), water management, biodiversity, eutrophication, resource depletion (biotic resources, abiotic/fossil resources, extraction), soil depletion.

- Structural mechanisms: financing (the current business model requiring partner companies for financing), the need for hiring, regulations, health and safety, working conditions (flexibility).

\subsection{Step 4: Sustainable wheel}

Each group has elaborated topics on a "sustainability wheel". The two sustainability wheels obtained are very different, both in the content and in their structure. The first group chose to build a common foundation for perma-engineering divided its wheel into three categories: skills, content and training cycle. Each category was divided in two "internal" and "external" elements. The internal elements were inside the wheel while the external were outside. The second group proposed a wheel divided into themes: industrial and territorial ecology, means necessary for training, pooling, recycling and reuse, 
study of climates, permaculture, stakeholders in training, study of climate and geopolitical issues, standards and regulations, health and safety, renewable energies, opportunities, training arrangements, low tech. Each theme was detailed in subpoints (between 1 and 6 subpoints).
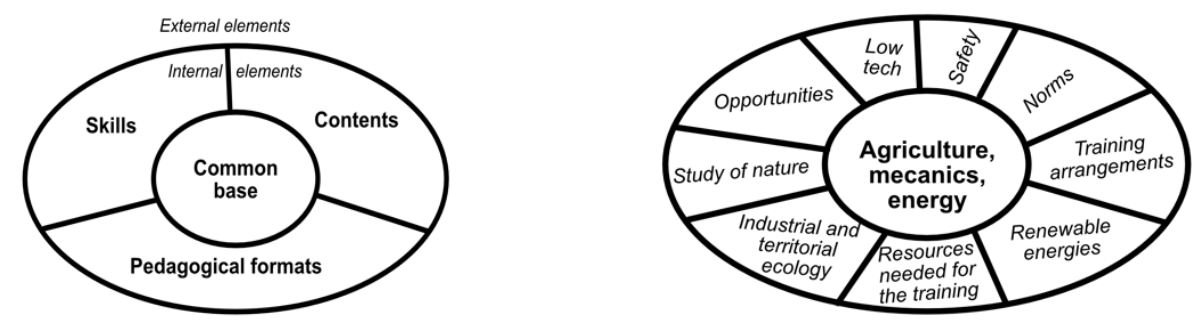

Figure 1. Structure of sustainable wheel of group 1 (left) and group 2 (right)

\section{ANALYSIS AND DISCUSSION}

\subsection{Global analysis}

This exploratory work was carried out using a heuristic approach. Indeed, the workshop was intended to be an animation (in a festive setting of the 25th anniversary of the University) and not specifically to write a scientific article. Nevertheless, the workshop was constructed methodically. The information obtained proved to be interesting to analyse and to use for the elaboration of a research hypothesis.

All those who participated in the workshop were particularly sensitive to the challenges of sustainability. Despite the good understanding of these issues, the scientific diagrams showed during the first step of the workshop seemed unknown to the participants.

The workshop was limited in time as it took place over one day (1h30 hours in the morning and $1 \mathrm{~h} 30$ hours in the afternoon). Therefore, no individual reflection space was offered during the workshop, only moments of collective reflection. During the feedback phase, some participants expressed this lack of individual moments of reflection.

\subsection{Step 1: Literature review presentation}

The explanations from the scientific literature seemed too complex in relation to the level of knowledge of the individuals present. Indeed, each slide presented a diagram describing an environmental dysfunction phenomenon (depletion of raw materials, disruption of the carbon cycle, and so on). Participants were unable to understand all the explanations due to their complexity. However, they asked a re-explanation by little groups during the workshop's constraint expression phase (phase 3). Thus, despite a certain complexity of the explanations in the introduction, this information given was relevant to the participants' reflections and productions.

\subsection{Step 2: Domain of expertise}

To have a sustainable approach one must be aware of the way's organisms (biotic factors) and their environments (abiotics factors) interact. This requires a multidisciplinary formation who offers a holistic vision of the environment. Thus, both groups wished to leave the CTI framework which let at most a binary combination of study fields, and this was done in the sense that one of the groups chose to reject the themes proposed by the CTI while the other group broke the rules of themes combination. These choices are significant, and it could be interesting to analyse furthermore why the participants felt « cramped » in the CTI framework when they had to take sustainability.

\subsection{Step 3: Mind map of constraints}

The part on constraints was complex. The participants returned several times to the sources that had been proposed in the introduction and were able to appropriate them by using them directly within their constraints.

\subsection{Step 4: Sustainable wheel}

The wheel of the first group seems very structured and has a very high level of abstraction, so it may seem difficult to build a formation from the rendering. The absence of CTI constraints allowed the group to create a training by detaching itself from what already exists. Strong points emerged from their work such as: 
- The need to break the understanding of the university as a "citadel" and to make it become an open place.

- A stronger anchoring in the territory so that the latter benefits from the knowledge produced within the university for its social development ("putting its training and professional future in context").

- A stronger link between students' associative activities and "classical" courses.

- A multidisciplinary and multi-stakeholder approach to training.

The second group produced a wheel with more content but less structure, where the highly technical content is brought up to the same level as the course format. This lack of structure can be attributed to the lack of time available to both groups to build their wheels. Here are the three areas that stand out for their content:

- The need for immersion in an economic context: the student must be employable at the end of his training course.

- Learning a strong knowledge base on the theme of sustainability.

- The presence of specific experimental sites within the university.

The first group having started from the idea of creating a common foundation, it was much easier for its members to detach themselves from the existing situation in universities. They started to talk about the issues of sustainability and tried to translate them into thematic of action plans. Due to a lack of time, the themes defined remain complex and a bit abstract. However, we can begin to see the emergence of atypical ideas. For instance, the fact of doing a foreign semester stick out in a "context where a carbon budget is to be respected". Ecological rationality will oblige students to travel to a foreign country slower and therefore to manage this journey as an integral part of their whole semester experience. This challenge may seem easy for European countries but will be much less so for countries in Asia or America. Alternative means will, therefore, must be put in place.

On the contrary, the second group chose to start from the chosen field of expertise (agriculture, mechanics and energy) to go back to the issues of sustainability. The group, therefore, established itself in existing fields of activity (farms, agricultural mechanics) and started from technical needs to try to achieve the challenges of ecological transition. This approach positions itself within the existing system and makes it difficult to detach oneself from it to find appropriate modifications to address the issues of ecological transition. This group has therefore made proposals that can be anchored both in a strong sustainability perspective and a weak sustainability perspective.

All the results obtained during the workshop (materials created by the participants) as well as details of the participant's profiles have been kept and can be given on request.

\section{CONCLUSIONS}

This workshop is an exploratory experiment, as it involves a restricted number of actors. We can conclude that participants faced difficulties positioning themselves within the imposed CTI framework because they had the feeling that this framework could not let them reach the issues of strong sustainability. Following this workshop, the hypothesis we can make is that the disciplinary approach limits the possibilities of the evolution of engineering education. This disciplinary approach has been chosen by institutional frameworks. These frameworks can, therefore, constrain thinking for strong evolutions of training. Ecology being a holistic approach involving disciplines other than those proposed by the French institutional framework CTI, it would be interesting to evaluate the relevance of this framework for designing training courses addressing environmental and social issues. This heuristic experiment, therefore, opens new research perspectives in the field of the evolution of engineering education and institutional frameworks accompanying higher education institutions.

\section{REFERENCES}

[1] Bonneuil, C. and Jean-Baptiste, F. 2013. L'Evénement Anthropocène: La Terre, l'histoire et nous. Seuil.

[2] Court, V. and Florian, F. 2017. 'Long-Term Estimates of the Energy-Return-on-Investment (EROI) of Coal, Oil, and Gas Global Productions'. Ecological Economics 138 (August): 145-59. https://doi.org/10.1016/j.ecolecon.2017.03.015.

[3] Georgescu-Roegen, N. 1971. The Entrophy Law and the Economic Process in Retrospect. Harvard University Press.

[4] Kümmel, R. 2011. The Second Law of Economics: Energy, Entropy, and the Origins of Wealth. 
Springer Science \& Business Media.

[5] Meadows, D. H., Meadows, D.L., Randers, J. and Behrens, W.W. 1972. 'The Limits to Growth; A Report for the Club of Rome's Project on the Predicament of Mankind'. New York: Universe Books.

[6] Chan, A.D.C, and Fishbein, J. 2009. 'A Global Engineer for the Global Community' 1 (2): 7.

[7] Eggermont, M. 2011. 'Engineering Reasoning and Visualization as Analysis Tools for BOP Design', 27.

[8] Blessing, L.T.M., and Chakrabarti, A. eds. 2009. 'DRM: A Design Research Methodology'. In DRM, a Design Research Methodology, 13-42. London: Springer. https://doi.org/10.1007/978-184882-587-1_2.

[9] Vérin, H. 1993. La Gloire des ingénieurs. Albin Michel. 